\title{
The effect of hydroxyurea on the expression of the common fragile site at $3 \mathrm{p} 14$
}

\author{
ZU-AN YAN, XINZHI LI, AND XIANTING ZHOU \\ From Institute of Genetics, Academia Sinica, Beijing, China.
}

SUMmary Hydroxyurea (HU) is an inhibitor of DNA synthesis, which can inhibit the enzyme ribonucleotide reductase, reduce the syntheses of all four deoxyribonucleoside diphosphates (dNDP), and disturb the balance of the dNTP pool. We have studied the effect of HU on the common fragile site at 3p14 (FRA3B) and have found that G2 treatment with HU increased not only the frequency of chromosomal aberration but also the expression of FRA3B in both complete and folate deficient media. There is a synergistic effect between $\mathrm{HU}$ and growth in folate deficient medium on the induction of FRA3B. Our results suggest that the inhibition of DNA repair, including the inhibition in G2 phase, plays an important role in the expression of FRA3B, supporting other authors' data on the effect of other DNA repair inhibitors, such as aphidicolin, caffeine, 1- $\beta$-D-arabinofuranosylcytosine, and 5-fluorodeoxyuridine, on the expression of FRA3B.

Common fragile sites, sometimes called 'hot points' in previous articles, are non-random chromosome lesions occurring at specific chromosome sites, for example, $3 \mathrm{p} 14,6 \mathrm{q} 26$, and $16 \mathrm{q} 23 .{ }^{1-3}$ Some inhibitors of DNA repair, such as 1- $\beta$-D-arabinofuranosylcytosine (araC), ${ }^{4}$ caffeine (caff) ${ }^{5}$ aphidicolin (Aph), ${ }^{6}$ and 5-fluorodeoxyuridine (FUdR), ${ }^{78}$ can induce the expression of common fragile sites including the fragile site at 3p14 (FRA3B).

Hydroxyurea (HU) is a DNA synthesis inhibitor, acting by inhibiting the enzyme ribonucleotide reductase, which catalyses the reduction of ribonucleoside diphosphates to the corresponding deoxyribonucleoside diphosphates. It can increase the frequencies of both spontaneous and induced chromosomal aberrations during G2 phase. ${ }^{9}$ To date, there have been no reports about the effect of HU on common fragile sites. In this paper, we report our studies on the effect of HU on the expression of FRA3B in which we found that $\mathrm{HU}$ increases not only the frequency of chromosomal aberrations but also significantly increases the expression of FRA3B.

\section{Materials and methods}

Lymphocyte cultures were established from fresh blood samples from eight healthy donors (four

Received for publication 26 November 1986.

Revised version accepted for publication 29 April 1987. males and four females). For each blood sample the cultures were divided into four groups: cultures in minimal essential complete medium $\left(\mathrm{FA}^{+}\right)$; cultures in complete medium treated with $\mathrm{HU}$ during $\mathrm{G} 2$ phase $\left(\mathrm{FA}^{+}+\mathrm{HU}\right)$; cultures in minimal essential folate deficient medium $\left(\mathrm{FA}^{-}\right)$; and cultures in folate deficient medium treated with HU during G2 phase $\left(\mathrm{FA}^{-}+\mathrm{HU}\right)$.

The cultures in folate deficient medium were set up by adding $0.5 \mathrm{ml}$ of heparinised venous blood to flasks containing $5 \mathrm{ml}$ of minimal essential medium without folic acid (MEM-FA) (Gibco), $0.25 \mathrm{ml}$ newborn calf serum, $0.05 \mathrm{ml}$ glutamine $(0.03 \mathrm{~g} / \mathrm{ml})$, $0.05 \mathrm{ml}$ penicillin and streptomycin $(10000 \mathrm{IU} / \mathrm{ml})$, and $0.15 \mathrm{ml}$ of PHA (Gibco). For the cultures in complete medium, $0.06 \mathrm{ml}$ folic acid $(0.1 \mathrm{mg} / \mathrm{ml})$ was added to folate deficient medium at a final concentration of $1 \mathrm{mg} / \mathrm{l}$.

The cultures were incubated for 96 hours at $37^{\circ} \mathrm{C}$. For the HU treated cultures, $\mathrm{HU}$ was added at a final concentration of $4 \times 10^{-3} \mathrm{~mol} / 1$ two hours before harvest. Colcemid at a final concentration of $0.3 \mu \mathrm{g} / \mathrm{ml}$ was added to all cultures for the last hour.

The slides were stained with Giemsa and 200 metaphases with 45 to 47 centromeres from each group of cultures were examined. All types of chromosome aberration, including chromatid gaps and isochromatid gaps, and FRA3B were scored. Some breaks at 3 p14 were confirmed by G banding (figure). 

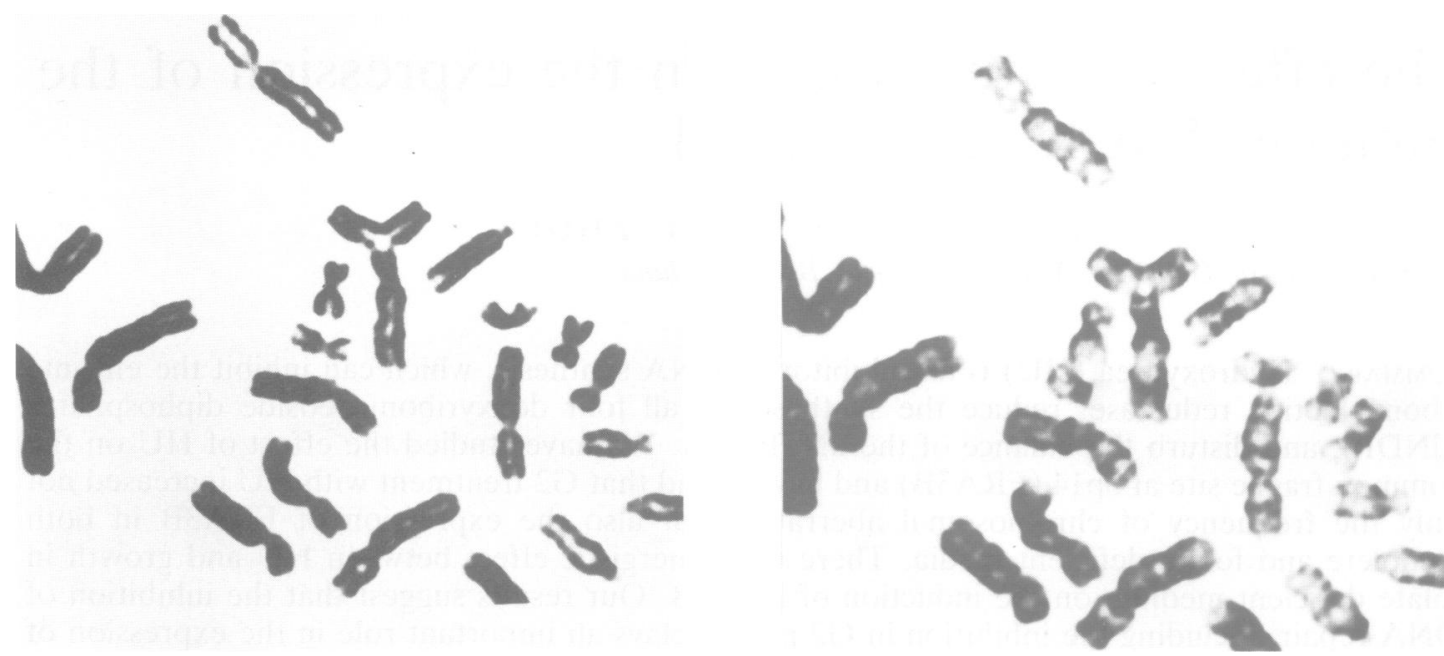

FIGURE Chromosome triradial at 3p14 in MEM-FA. Left: Giemsa stain; right: G banding.

\section{Results and discussion}

According to the widened definition and classification of fragile sites, ${ }^{10}$ we would call the non-random gaps and breaks on human chromosomes which were studied in our laboratory ${ }^{1-3}$ common fragile sites instead of 'hot points'.

$\mathrm{HU}$, an inhibitor of both replicative and repair DNA synthesis, can inhibit the enzyme ribonucleotide reductase, reduce the synthesis of all four deoxyribonucleoside diphosphates (dNDP), and deplete the dNTP pool in cells. This effect would limit DNA synthesis activity leading to a dramatic decrease in replicative DNA synthesis. The results of the study of Erixon and Ahnström ${ }^{11}$ also clearly indicate that $\mathrm{HU}$ affects repair synthesis. However, the idea that HU inhibits DNA repair has been challenged by the work of Smith. ${ }^{12} \mathrm{He}$ found that repair synthesis was increased by 25 to $40 \%$ in $\mathrm{HU}$ treated cells over a wide range of UV doses and post UV incubation times. Even $100 \mathrm{mmol} / \mathrm{l} \mathrm{HU}$ did not significantly decrease repair synthesis. To date, the mechanism of inhibition of DNA repair by $\mathrm{HU}$ is not yet fully understood. As suggested by Erixon and Ahnström, ${ }^{11}$ the rate of DNA repair polymerisation falls off as the size of the dNTP pool is reduced by $\mathrm{HU}$. The exonucleolytic digestion or DNA strand displacement proceeds faster than the polymerisation does. Thus, ligation is delayed, patch size increases, ${ }^{13}$ and the repair site remains open five times longer than normal. ${ }^{11}$ In general, the reduction of dNTP pool size by $\mathrm{HU}$ acts on DNA repair by lengthening the time required to complete a repair event but does not materially $\vec{\oplus}$ affect the total amount of repair synthesis. This. would increase the number of repair sites unligated at a given time, ${ }^{12}$ causing the accumulation of single strand DNA breaks and chromosome aberrations.

The frequencies of chromosomal aberrations in the four culture groups are listed in table 1 . In the $\mathrm{FA}^{+}+\mathrm{HU}$ and $\mathrm{FA}^{-}+\mathrm{HU}$ groups, the frequencies of $\overrightarrow{\overrightarrow{7}}$ chromosome aberrations, including gaps and iso- $\frac{O}{3}$ chromatid gaps, are obviously higher than those in the corresponding controls. Our results are consistent with the reports of Kihlman and Natarajan 9 and Kihlman et $a^{14}$ and indicate that in this experiment the DNA repair in G2 is inhibited.

The expression of FRA3B induced by HU is 3 . shown in table 2 . The mean frequencies of FRA3B in the $\mathrm{FA}^{-}+\mathrm{HU}$ and $\mathrm{FA}^{+}+\mathrm{HU}$ groups are very

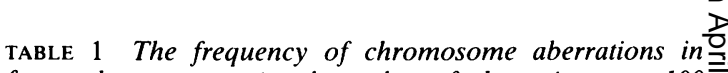
four culture groups (total number of aberrations per $100 \mathrm{~N}$ metaphases).

\begin{tabular}{|c|c|c|c|c|}
\hline Subjects & $\mathrm{FA}^{+}$ & $F A^{+}+H U$ & $F A^{-}$ & $F A^{-}+H U$ \\
\hline 1 & $5 \cdot 5$ & $29 \cdot 0$ & $8 \cdot 5$ & $65 \cdot 0$ \\
\hline 2 & $2 \cdot 0$ & $19 \cdot 5$ & $7 \cdot 5$ & $99 \cdot 5$ \\
\hline 3 & $2 \cdot 5$ & $7 \cdot 5$ & $3 \cdot 0$ & $36 \cdot 5$ \\
\hline 4 & $3 \cdot 0$ & $11 \cdot 5$ & $5 \cdot 5$ & 63.5 \\
\hline 5 & 0 & $16 \cdot 5$ & $9 \cdot()$ & $57 \cdot()$ \\
\hline 6 & $2 \cdot 0$ & $20 \cdot 5$ & $20 \cdot 0$ & $121 \cdot 0$ \\
\hline 7 & 0.5 & $7 \cdot 5$ & $4 \cdot 5$ & $15 \cdot 5$ \\
\hline 8 & 0 & $4 \cdot 5$ & $2 \cdot 5$ & $19 \cdot 5$ \\
\hline Mean (SD) & $1.94(1.84)$ & $14 \cdot 56(8 \cdot 30)^{*}$ & $7 \cdot 56(5 \cdot 58)$ & $59.69(36.84)$ \\
\hline
\end{tabular}


TABLE 2 The frequency of FRA3B in four culture groups (total number of FRA3B per 100 metaphases).

\begin{tabular}{lllll}
\hline Subject & $F A^{+}$ & $F A^{+}+H U$ & $F A^{-}$ & $F A^{-}+H U$ \\
\hline 1 & $1 \cdot 5$ & 11.5 & $2 \cdot 0$ & $21 \cdot 0$ \\
2 & 0 & $4 \cdot 0$ & $3 \cdot 0$ & $25 \cdot 0$ \\
3 & 0 & 0 & $1 \cdot 0$ & $8 \cdot 0$ \\
4 & 0 & $3 \cdot 5$ & $2 \cdot 5$ & $23 \cdot 5$ \\
5 & 0 & $5 \cdot 0$ & $2 \cdot 5$ & 19.0 \\
6 & 0 & $6 \cdot 0$ & $5 \cdot 5$ & $41 \cdot 5$ \\
7 & 0 & $2 \cdot 0$ & $0 \cdot 5$ & $5 \cdot 0$ \\
8 & 0 & 0.5 & 1.0 & $8 \cdot 5$ \\
Mean (SD) & $0 \cdot 19(0.53)$ & $4.06(3.66)^{*}$ & $2.25(1.58)$ & $18.94(11.91)^{\dagger}$
\end{tabular}

${ }^{*} 0.05>\mathrm{p}>0.01$ compared with the $\mathrm{FA}^{+}$group.

$\dagger \mathrm{p}<0.002$ compared with the $\mathrm{FA}^{-}$group.

much higher than those in the $\mathrm{FA}^{-}(\mathrm{p}<0.002)$ and the $\mathrm{FA}^{+}(\mathrm{p}<0.05)$ groups, respectively. In the first 200 metaphases scored, the positive rate of FRA3B in the eight subjects studied was $88 \%(7 / 8)$ for the $\mathrm{FA}^{+}+\mathrm{HU}$ group and $13 \%(1 / 8)$ for the $\mathrm{FA}^{+}$group. These findings indicate that $\mathrm{HU}$ can induce the expression of FRA3B and enhance its frequency both in folate deficient and in complete medium.

Aph and araC are both inhibitors of DNA repair by inhibiting the enzyme DNA polymerase $\alpha .{ }^{5-18}$ The frequencies of both spontaneous and induced chromosomal aberrations can be increased by Aph and araC during G2 phase. $^{9}$ The significantly increased frequencies of FRA3B induced by the treatment with araC or Aph were also found in lymphocytes cultured in vitro. ${ }^{4} 6$ These results indicate that the low DNA polymerase $\alpha$ activity and inefficient repair of DNA synthesis during the cell cycle or $\mathrm{G} 2$ phase play a role in the expression of FRA3B.

Caffeine can shorten the time available for repair and increase the frequencies of both spontaneous and induced chromosomal aberrations during G2 phase. ${ }^{9}$ Yunis and Soreng ${ }^{5}$ found that caffeine is an inhibitor of DNA post-replication repair and that it can enhance the expression of common fragile sites, especially at 3p14 and $16 \mathrm{q} 23$. FUdR is a powerful DNA repair inhibitor, specifically inhibiting thymidylate synthetase which catalyses the synthesis of thymidylic acid from deoxyuridylic acid. It can increase the frequencies of both spontaneous and induced chromosomal aberrations during G2 phase. ${ }^{9}$ Daniel et $a l^{7}$ and Smeets et $a l^{8}$ found that FUdR can enhance the expression of FRA3B and other sites. The effect of DNA repair inhibitors, HU, Aph, araC, caffeine, and FUdR on the expression of common fragile sites might suggest that inefficient DNA repair, including inefficient DNA repair synthesis during G2 phase, plays a very important role in the expression of FRA3B.
As with HU, G2 treatment with 2'-deoxyadenosine (dAdo) can increase the frequency of chromosomal aberrations. ${ }^{19}$ Although the chemical structures of HU and dAdo vary significantly, both inhibit DNA repair synthesis by inhibition of the enzyme ribonucleotide reductase. On the basis of the effect of HU on FRA3B, we predict that dAdo could also induce the expression of FRA3B.

When lymphocyte cultures are maintained in complete medium, the rate of FRA3B in a population is very low. Although araC could induce FRA3B in complete medium, the rate of FRA3B in the seven blood donors studied was only $57 \%(4 / 7)$ and there was no significant difference between araC treated and untreated groups (table 3$)^{4}$; the induction of FRA3B by $\mathrm{HU}$ in complete medium seems to be more efficient than by araC. FRA'3B was observed in seven of eight blood donors studied and the frequency of the HU treated group was significantly different from that of the HU untreated group $(p<0.05$, table 2$)$. It appears that inhibition of ribonucleotide reductase by $\mathrm{HU}$ has more effect on the expression of FRA3B than inhibition of DNA polymerase $\alpha$ by araC.

In this experiment synergism between $\mathrm{HU}$ and growth in the folate deficient medium was tested. According to the formula of Kihlman and Andersson ${ }^{15}: \mathrm{Cf}=\mathrm{Ei} 1+\mathrm{i} 2 /(\mathrm{Ei} 1+\mathrm{Ei} 2)$, where $\mathrm{Cf}$ is the combination factor, Ei1 $+\mathrm{i} 2$ is the effect of the combined treatment, and Ei1+Ei2 the sum of the effects of the inhibitors i1 and i2 alone. The Cf of $\mathrm{HU}$ and folate deficiency in combination is $3 \cdot 1$. This Cf value indicates that there is a synergistic effect between $\mathrm{HU}$ and growth in folate deficient medium on the induction of FRA3B. There are also similar synergistic effects between araC, Aph, or caffeine and growth in folate deficient medium. ${ }^{4-6}$ It seems that more DNA damage is induced when cells grow in folate deficient medium. Folic acid is converted to 5,10 -methylenetetrahydrofolate in vivo. The latter serves as a co-enzyme of thymidilate synthetase which catalyses the methylation of dUMP to dTMP. Folic acid deficiency would block the methylation of

TABLE 3 Comparison of the effect of $H U$ and araC on the frequencies of FRA3B (number of FRA3B per 100 metaphases).

\begin{tabular}{lllrl}
\hline & $F A^{+}$ & $p$ & $F A^{-}$ & $p$ \\
\hline $\mathrm{HU}^{-*}$ & $0.19(0.53)$ & & $2.25(1.58)$ & \\
$\mathrm{HU}^{+*}$ & $4.06(3.66)$ & $<0.05$ & $18.94(11.91)$ & $<0.002$ \\
& & & $1.79(1.35)$ & \\
$\operatorname{araC}^{+}+$ & $0.21(0.57)$ & & $14.14(9.24)$ & $<0.005$ \\
$\operatorname{araC}^{+}+$ & $1.71(2.58)$ & $>0.05$ & &
\end{tabular}

*Eight blood donors were studied (this report).

tSeven blood donors were studied. 
dUMP to dTMP, limit the pool of dTTP, and enlarge the pool of dUTP, resulting in the misincorporation of uracil into DNA. The uracil containing DNA in the region 3p14 is responsible for the expression of FRA3B. ${ }^{3}$ If the capacity for DNA repair is normal, most of this damage would be repaired, only the occasional lack of repair inducing the expression of FRA3B. When DNA repair is inhibited, most damage could not be repaired and would induce the expression of FRA3B. Interestingly, inhibition of DNA repair by HU could also induce the expression of FRA3B in the complete medium; this finding suggests that misincorporation of uracil into DNA is not the only mechanism responsible for the expression of FRA3B.

This work was supported by the National Foundation of Natural Science of China 3860196.

\section{References}

1 Li N, Wu Y, Zhou XT. Human chromosome hot point. V. The effect of four nucleotides on chromosomes in folate-free medium. Hum Genet 1986;74:101-3.

2 Zhou XT, Xu B, Chu C, Xia G, Li N, Sha R. Human chromosome hot points. I. Hot point at 3 p14 in three populations. Hum Genet 1984;67:249-51.

3 Li N, Zhou XT. Human chromosome hot points. IV. Uridine induced hot point breaks at $3 \mathrm{p} 14$ and $16 \mathrm{q} 23-24$ and increased expression of fragile site $\mathrm{Xq} 27$ in folate-free medium. Hum Genet 1985;71:363-5.

${ }^{4} \mathrm{Li}$ XZ, Yan ZA, Zhou XT. The effect of $1-\beta-D-$ arabinofuranosylcytosine on the expression of the common fragile site at $3 \mathrm{p} 14$ Hum Genet 1986;74:444-6.

5 Yunis JJ, Soreng AL. Hot spots of the human genome. Am J Hum Genet 1984;36:40.

6 Glover TW, Berger C, Coyle J, Echo B. DNA polymerase $\alpha$ inhibition by aphidicolin induces gaps and breaks at common fragile sites in human chromosomes. Hum Genet 1984;67: 136-42.

7 Daniel A, Ekblom L, Philips S. Constitutive fragile sites 1p31, $3 \mathrm{p} 14,6 \mathrm{q} 26$ and $16 \mathrm{q} 23$ and their use as controls for false-negative results with the fragile (X). Am J Med Genet 1984;18:483-91.

8 Smeets DFCM, Scheres JMJC, Hustinx TWJ. The most common fragile site in man is 3p14. Hum Genet 1986;72:215-20.
${ }^{9}$ Kihlman BA, Natarajan AT. Potentiation of chromosomal $\overrightarrow{\bar{n}}$ alterations by inhibitors of DNA repair. In: Collins A, Downes $\stackrel{\mathcal{P}}{+}$ CS, Johnson RT, eds. DNA repair and its inhibition. Oxford:음 IRL Press, 1984:319-39.

10 Berger R, Bloomfield CD, Sutherland GR. Report of the $\frac{\bar{\sigma}}{\bar{s}}$ committee on chromosome rearrangements in neoplasia and on $\vec{\nabla}$ fragile sites. HGM8. Cytogenet Cell Genet 1985;40:490-535. ¿ి

"Erixon K, Ahnström G. Single-strand breaks in DNA during repair of UV-induced damage in normal human and xeroderma $\mathcal{C}$ pigmentosum cells as determined by alkaline DNA unwinding $\overrightarrow{0}$ and hydroxylapatite chromatography: effects of hydroxyurea, 5fluorodeoxyuridine and $1-\beta-D-$ arabinofuranosylcytosine on the $\vec{\omega}$ kinetics of repair. Mutat Res 1979;59:257-71.

12 Smith CA. Analysis of repair synthesis in the presence of inhibitors. In: Collins A, Downes CS, Johnson RT, eds. $D N A$ repair and its inhibition. Oxford: IRL Press, 1984:51-71.

13 Snyder RD, Van Houten B, Regan JD. The accumulation of $A$ DNA breaks due to incision; comparative studies with various $\overrightarrow{0}$ inhibitors. In: Collins A, Downes CS, Johnson RT, eds. DNA ir repair and its inhibition, Oxford: IRL Press, 1984:13-33.

14 Kihlman BA, Hansson K, Palitti F, Andersson HC, Hartleyasp

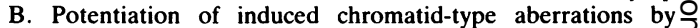
hydroxyurea and caffeine in $G_{2}$. In: Natarajan $A T$, Obe $G_{\text {, }}$, Altmann $\mathrm{H}$, eds. Progress in mutation research. Vol 4. Amsterdam: Elsevier Biomedical Press, 1982:11-24.

15 Ikegami S, Taguchi T, Ohashi M, Nagano H, Mano Y. Aphidicolin prevents mitotic cell division by interfering with the activity of DNA polymerase $\alpha$. Nature 1978;275:458-60.

16 Collins ARS, Downes CS, Johnson RT. Introduction: an $\overrightarrow{0}$ integrated view of inhibited repair. In: Collins $A$, Downes $C S, \infty$ Johnson RT, eds. DNA repair and its inhibition. Oxford: IRL. Press, 1984:1-11.

17 Fram RJ, Kufe DW. The effect of inhibitors of DNA synthesis on DNA repair. In: Collins A, Downes CS, Johnson RT, eds. DNA repair and its inhibition. Oxford: IRL Press, 1984:95-108.

18 Scovassi AI, Plevani P, Bertazzoni U. Eukaryotic DNA poly- ํำ merases. Trends Biochem Sci 1980;5:335-7.

19 Kihlman BA, Andersson HC. The effect of $\mathrm{G}_{2}$-treatments with 2 -deoxyadenosine on the frequency of chromatid aberrations in human lymphocytes depends on the type of culture. Chromo-3 soma 1984;90:239-42.

20 Kihlman BA, Andersson HC. Synergistic enhancement of the frequency of chromatid aberrations in cultured human lympho- cytes by combinations of inhibitors of DNA repair. Mutat Res 1985;150:313-25.

Correspondence and requests for reprints to $\mathrm{Dr} \mathrm{Zu}$ an Yan, Institute of Genetics, Academia Sinica, Beijing, China. 